\title{
NOVAS TECNOLOGIAS NO CONTEXTO ESCOLAR
}

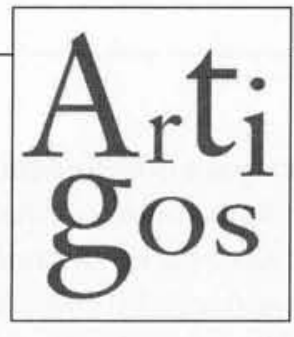

nacionais

\section{Uso de novas tecnologias na escola descarta o deslumbramento tecnicista para impor-se como necessidade de democratização do conhecimento e do exercício da cidadania}

As novas tecnologia ganharam espaço na sociedade contemporânea. $\mathrm{O}$ avanço das novas descobertas neste campo é muito grande. Enquanto, em 1950, a primeira televisão em preto-e-branco chegava ao Brasil, hoje, apenas cinqüenta anos depois, fala-se em TV interativa. Estamos na era da informação e da imagem. Numa mistura de fascinação e de medo, a humanidade convive com inúmeras modificações, passando a questionar até o significado do real, uma vez que imagem (representação) e realidade apresentam-se incorporadas uma na outra. Aquilo que parecia filme de ficção científica, hoje é uma atividade cotidiana de muitos indivíduos. Sem sair de casa já é possível, por exemplo, fazer todo serviço bancário; consultar as mais completas bibliotecas e livrarias; comprar, vender; conversar com um astronauta no espaço, ler jornais de outros estados, assim que acabam de ser editados.

$\mathrm{O}$ avanço acelerado das tecnologias tem alterado significativamente o modo de entender e de perceber o mundo. Os paradigmas da Modernidade são questionados, o homem manifesta-se com perplexidade diante de conceitos e valores que antes pareciam ter sido ampla- mente explorados, definidos. Até mesmo a noção de movimento deve ser reavaliada. Paul Virílio usa a viagem para exemplificar essa nova configuração de movimento e espaço. Para ele, a viagem passou a ser apenas intervalo.

“... mais rápido que o sol, o supersônico chega a Nova York antes de ter partido de Paris... Enquanto num outro tempo existiam ainda os três termos, partida, viagem e chegada, hoje restam dois, a partida e a chegada"'.

Essa verdadeira revolução dos meios de transporte, Rener Berger chama de telêmica: "promovem um deslocamento cada vez mais veloz com veículos cada vez mais sofisticados" ${ }^{2}$. Ainda na compreensão de Berger segundo Pretto: "a telêmica está para o corpo assim como a telemática (fruto da combinação da informática com a telefonia) está para as mensagens e ambas são comple-

\section{A AUTORA}

\section{Gelcivânia Mota Silva Morais}

Pedagoga, especialista em Metodologia do Ensino. Professora e Diretora da Faculdade de Educação de Serrinha - Universidade do Estado da Bahia-UNEB. 
mentares para o fenômeno que denomina de teletropismo, onde a circulação tornou-se a figura-chave da nova civilização: circulação dos automóveis, circulação das imagens, circulação da moda, tudo se move, dissolve, é substituído. Isto é o teletropismo, uma nova figura do nomadismo"3.

Essas diversas possibilidades de circulação de mensagens e de idéias contribuem para quebrar a unicidade do conceito linear de história, pois já é possível ver, ouvir e discutir as múltiplas visões de mundo, contar várias histórias. Neste contexto, nossos valores têm sido profundamente modificados, nossas concepções subitamente questionadas. Uma outra razão começa a ser gestada a partir do crescimento da comunicação e da informática, uma razão que nas palavras de Nelson Pretto ainda não está completamente definida, mas tem na globalidade e na integridade seus elementos mais fundamentais. Tais fatos permitem-nos concordar com o referido autor ao afirmar que a "Modernidade chegou em seu limite histórico".

As mudanças no contexto atual são geradas principalmente pelo surgimento de novas tecnologias da informação e da comunicação. Nicholas Negroponte ${ }^{4}$ caracteriza estas tecnologias como responsáveis pela desmaterialização da informação de átomos para bits. Como tão bem situa Monteiro. “(...) Lidamos com inúmeras coisas cuja existência já não é exatamente material. Onde está e como é nosso dinheiro quando fazemos uma transferência eletrônica entre contas bancárias? Onde se dá nossa conversa quando deixamos um recado numa secretária eletrônica? Quem são as pessoas com quem debatemos um tema na Internet? (elas existem mesmo?). (...) De repente, coisas que podíamos pegar, lugares onde podíamos ir, pessoas com quem podíamos contar, falar, viram imagens, conceitos, luzes, números, sons, CD-Rom"s.

Pierre Lévy denomina estas tecnologias de "tecnologias inteligentes" 6 , pois possibilitam um outro modo de pensar, uma outra forma de construção do conhecimento pautada numa lógica não mais linear, mas hipertextual. Um exemplo de tecnologia inteligente é a Internet, cujos dispositivos materiais permitem criar conexões artificiais que imitam o processo de funcionamento da mente humana.

As novas tecnologias fizeram emergir um outro logos, cujas características apontam para o rompimento da noção tempo-espaço tal como foi concebida pela ciência moderna, a convivência do local e nãolocal, o raciocínio estético, a discussão entre real/virtual.

Estaríamos então, após a instauração deste novo logos, fora da ordem mundial? Pelo contrário. Estamos diante de uma outra ordem pois a mixagem som/imagem/palavra exige uma outra postura, chamada por Babin ${ }^{7}$ de postura estéreo - que busca o equilíbrio entre a cultura letrada embasada numa lógica linear, cartesiana, mas que tem o seu valor, com a cultura do audiovisual, que enfoca outras dimensões do sujeito: $\mathrm{o}$ afeto, a imaginação e a subjetividade, o que torna possível perceber o homem em toda sua inteireza e complexidade.

3. BERGER, R. apud PRETTO, Nélson. Uma escola... op.cit. p. 36.

4. NEGROPONTE, Nicholas. apud SOARES Jr., Arnaud. O currículo como hipertexto. Revista de Educação. Centro de Estudos e Assesoria Pedagógica. CEAP. Ano 6, n. 20, mar., 1998.

5. MONTEIRO, Eduardo. Educação Virtual: indo onde homem algum jamais esteve. Revista de Educação. CEAP. Ano 5, n.19, dez., 1997. p. 84 .

6. LÉVI. Pierre. As tecnologias da inteligência: o futuro do pensamento na era da informática. Rio de Janeiro: Editora $34,1993$. 7. BABIN, Pierre, KOULOUMDYIAN, Marie Frace. Os novos modos de compreender - a geração do audiovisual e do computador. São Paulo: Paulinas, 1989. 
Para Lévy, uma tecnologia inteligente apresenta inúmeras conexões imitando a complexidade da mente humana numa estrutura hipertextual. Seria, então, um grande texto em forma de rede sem pontos iniciais, onde cada ponto apresenta a sua complexidade e é, em si mesmo, uma microrrede. Um hipertexto pode ser uma página, uma imagem, um gráfico. Constitui-se um conjunto de nós ligados em rede. Este ponto está ligado a esse, que por sua vez liga-se àquele, que retorna ao primeiro, ou seja, tudo está ligado a tudo e vai, pouco a pou$\mathrm{co}$, formando, construindo um conjunto.

Entender as tecnologias da informação e da comunicação nesta perspectiva implica superar a visão dicotomizada entre homem e máquina. Sem dúvida alguma estas tecnologias foram usadas, principalmente no espaço escolar, com a característica de um mero instrumento a serviço de uma formação castradora, rígida e congelada sob os pilares da disciplinaridade. Vista deste ângulo, as tecnologias serviriam para controlar a mente humana, para robotizar o homem. Freqüentemente, diversos autores utilizam o termo técnica quando desejam referir-se a um comportamento padrão, ditado pela lógica do mercado e não pelos princípios norteadores do crescimento humano. Alguns, inclusive, chegam a afirmar que a máquina substituirá definitivamente o homem. São os chamados apocalípticos, conforme Babin. Mas é preciso considerar os avanços favorecidos por estas tecnologias, principalmente no momento atual - em que vivemos a quarta geração destes veículos de comunicação chamados inteligentes.

\section{PAPEL DO EDUCADOR}

A partir de tal compreensão acreditamos que o educador precisa considerar o quanto as tecnologias alteram o cotidiano das pessoas, possibilitando um outro modo de compreender/interpretar o mundo; e compreender as possibilidades de uso destes multimeios, considerando as tecnologias como mediadoras de um processo educacional mais amplo, numa perspectiva de superação da visão tecnicista, instrumental, difundida na década de 70 .

De modo algum queremos assumir a posição daqueles que Babin chama de otimistas, para os quais as tecnologias, no âmbito educacional, representam a resolução de todos os problemas.

Algumas questões são de extrema relevância e merecem ser pensadas por parte dos educadores que não coadunam com a perspectiva da neutralidade científica, porém perseguem a definição de intenções, objetivos, finalidade condição primeira para $o$ ato pedagógico.

Pensar o avanço tecnológico do mundo contemporâneo em face da escola atual pressupõe uma investigação sobre algumas questões: não basta apenas levar os modernos equipamentos para a escola, como querem algumas propostas oficiais. Não é suficiente adquirir televisões, videocassetes, computadores, sem que haja uma mudança básica na postura do educador. Isto reduzirá as novas tecnologias a simples meios de informação.

É preciso mais! A comunicação precisa ser instaurada, desejada, conquistada. Faz-se necessário entender que o educando deve ser o centro do processo educativo. Ele é histórico, ativo e como tal, a atenção não pode centrarse apenas no instrumento, na técnica.

Assim como é vã a tentativa de ignorar as profundas transformações decorrentes da inserção das novas tecnologias na sociedade atual, é também extremamente equivocada a 
crença de que a mera aquisição dos instrumentos técnicos bastam para acompanhar essas modificações. Esqueçam lápis, canetas, borrachas! Vivam os monitores! Bem-vindos ao reino das teclas, das televisões, dos microcomputadores. Não é este o discurso que a escola deve adotar, embora não se possa negar a influência das tecnologias na educação. Elas estão alterando o cotidiano da sala de aula. Entretanto, como tão significativamente afirma Toschi: "estes mesmos instrumentos não prescindem das funções mais elementares que a escola desenvolve que são a leitura e a escrita" " mas, ao contrário, permitem a ampliação desses conceitos. Muito além da simples interpretação de signos lingüísticos, hoje, le-se o mundo através das imagens, como também já é possível escrever usando a filmadora, a máquina fotográfica, o cinema, o computador.

A escola do terceiro milênio deve, necessariamente, considerar a influência das imagens no cotidiano do educando. $E$ mais, deve observar o reflexo dessa influência de compreender a realidade na sua organização perceptiva, sensorial e cognitiva.

"Enquanto a neve, por exemplo, era conhecida nos países tropicais através de cartões, cartazes e descrições escritas, hoje ela é vista nas telas de TV, nos monitores de vídeo e pode ser sentida através de equipamentos virtuais. Estas diferenças devem ser levadas em conta no processo de produção do saber" .

Ao possibilitar a interação com o que se vê e ouve, as novas tecnologias avançaram significativamente no processo educacional.
Toschi salienta ainda que: "do raciocínio linear, seqüencial, exigido por métodos expositivos convencionais, tem-se a possibilidade na utilização de computadores em sala de aula, por exemplo, de trabalhar com métodos interativos, onde é possível parar, interromper a história no meio e abrir uma janela para outro ponto pelo qual se mostre curiosa. Dessa forma, a construção do raciocínio não é mais linear, mas multidimensional" 10 .

Portanto, hoje, há uma outra forma de compreender e construir conceitos em relação às novas tecnologias. A escola precisa privilegiar a discussão desses novos conceitos.

\section{TECNOLOGIAS E CIDADANIA}

Outra questão importante é a necessidade emergente de reflexão sobre o desemprego e a exclusão gerados a partir do crescimento destas tecnologias. Sem acesso a grande parte dos avanços tecnológicos, temos, hoje, um novo tipo de excluído. Cristóvam Buarque, ex-reitor da UnB, referindo-se ao Brasil e à mídia televisiva, ilustra bem este quadro. Para ele, os futuros grupos sociais que surgirão (ou já surgiram?) em função da centralização dos meios de informação podem ser divididos entre parabólicos e metabólicos. "Os parabólicos vão ter uma televisão com quatrocentos canais, vão ver os filmes que querem, os debates com os filósofos que quiserem, ficarão cultos com a televisão; e os metabólicos, que terão a televisão apenas como uma extensão dos seus braços, uma televisão que não vai ajudar a pensar, ao contrário, vai levar a não pensar""I .

Mesmo discordando desta linearidade na recepção, pois o sujeito é histórico e exis- 
tem outros fatores além da mensagem em si que permitem modificá-la, ressignificá-la, o alerta de Buarque é válido. A inserção no mundo do trabalho requer um conhecimento mínimo sobre as transformações mundiais. Os avanços científicos nesta sociedade, denominada sociedade do conhecimento, acontecem, mas mantém-se um grupo minoritário decidindo quem aprende primeiro e o que é aprendido.

Rifkin $^{12}$ aponta para a extinção dos empregos, o surgimento de prestadores de serviços capazes de realizar inúmeras atividades diferenciadas, sem um vínculo empregatício definido. Isto, claro, resume-se a uma minoria.

Grande parte da população mundial economicamente ativa estará brevemente fora do mercado de trabalho. São os chamados tecno-desempregados que somam-se aos antigos excluídos e buscam a inserção no mercado de trabalho. Incorporando-se a anseios e lutas coletivas dos trabalhadores como a luta pela terra, a luta pelo pão nosso de cada dia, tem-se hoje a luta pelo acesso aos espaços de conhecimento.

Numa sociedade desigual marcada pela divisão de classes sociais, é preciso que os educadores reflitam sobre:

- contexto de emergência de novos paradigmas; desenvolvimento tecnológico que pode ser utilizado numa formação sólida, que permita ao aluno inserir-se no mundo do trabalho com uma percepção mais crítica;

- como a escola deve direcionar o tra- balho pedagógico para formar cidadãos e não tecno-burocratas.

Historicamente os educandos que não têm acesso às informações, que fazem parte do grupo menos privilegiado da sociedade, já nascem inseridos num contexto de desqualificação da sua força de trabalho. As relações sociais travadas por eles são marcadas pela desigualdade e negação do direito de ser cidadão. Resgatar esta cidadania é fundamental. A escola deve estar à frente deste desafio que aliás, como nos lembra Franco ${ }^{13}$, é o desafio do homem moderno. Construir uma nova proposta curricular, pautada na afirmação da identidade, no respeito pelas diferenças, na construção de oportunidades iguais é, portanto, um requisito básico para se alcançar esse objetivo. Cidadania pressupõe eqüidade e justiça.

"A cidadania é o exercício de adaptações entre os desejos e deveres do eu-pessoal e do eusocial. Na formação do cidadão para viver no mundo contraditório que o progresso vem construindo não cabem mais as ditaduras de pontos de vista. Lidar com as pluralidades é o grande desafio que se apresenta ao homem do futuro"14 .

\section{NOVO CURRÍCULO, AMPLAS POSSIBILIDADES}

Diante do novo quadro que surge no cenário escolar em detrimento do avanço das tecnologias, qual o melhor caminho para o educador? Arrisco a proposta de construção de um currículo numa perspectiva hipertextual. Entender o currículo sob este prisma implica vê-lo rico, pleno de significados decorrentes das experiências dos indivíduos e das relações destes com outros.

12. RIFKIN, Jeremy. O fim dos empregos: o declínio inevitável dos níveis de empregos e a redução da força global de trabalho. São Paulo: Makron Books, 1995.

13. FRANCO, Marília. Linguagens audiovisuais e cidadania. Comunicação \& Educação. São Paulo: CCA-ECA-USP/Moderna, n. 9 , maio/ago. 1997 p. 120.

14. FRANCO, Marília. Linguagens... op. cit.

15. SOARES Jr., Arnaud. O curriculo como hipertexto... op. cit. p. 86. 
O currículo seria então como um hipertexto, assumindo, de acordo com Soares $^{15}$, a função de uma interface. A escola deve propor um ensino que interligue razão-emoção, sentimento-pensamento, numa perspectiva de interatividade, tal como a tecnologia inteligente faz no hipertexto, na Internet.

O professor, percebendo o currículo nesta lógica hipertextual, abriria possibilidades para troca de idéias, de informações, de saberes múltiplos, diferentes e, por isso mesmo, ricos. Os conteúdos trabalhados deixam de ser aqueles direcionados por um poder hegemônico centralizador para ser o conteúdo que responda inicialmente às exigências daquele grupo social e, em seguida, possibilite a inserção dos membros deste grupo no mundo globalizado. Formar um cidadão trabalhador local e global é tarefa da escola no mundo contemporâneo.

$O$ educador de hoje precisa entender que a produção coletiva só tem sentido se for para um pensar coletivo, que a escola não se resume nela mesma, sendo necessário repensar a dicotomia entre escola formal e escola informal para perceber os outros espaços educativos tão ou mais significativos que a própria escola. A articulação dos conteúdos precisa superar a relação hierarquizada e linear estabelecida pela escola - primeiro aprende-se isto, depois aquilo, de forma seqüenciada e serial - e partir para uma organização curricular transversal, numa perspectiva de janelas. Como em computadores onde se abre uma janela, estuda-se, redige-se um texto e depois fecha-se, para ir a uma outra, retorna-se à primeira, vai-se para uma terceira, volta-se num constante movimento de ir e vir. Logo, as possibilidades não se esgotam. A primeira janela existe independente da terceira e esta existe ao mesmo tempo que a primeira.

Trabalhar os conteúdos em sala de aula nesta perspectiva significa respeitar as diferenças, os gostos e interesses dos alunos. $\mathrm{O}$ professor aponta demandas, mas é o interesse do grupo que direciona o processo e, por sua vez, estes mesmos interesses farão com que haja modificações na forma de o educador pensar/compreender o mundo. É, pois, um movimento dialético intelectual, profissional e emocional dos sujeitos envolvidos no processo educativo. Um currículo nestes moldes constitui-se, conforme Soares ${ }^{16}$, um espaço multirreferencial de aprendizagem. Ou seja, permite uma multiplicidade de olhares sobre os objetos do conhecimento, fortalece a heterogeneidade do grupo, torna o caminho coletivo e respeita as diferenças.

Efetivar um currículo com concepção multirreferencial implica investir na pesquisa como suporte para a formação dos educadores. Educadores que possam ser capazes de gestar projetos pedagógicos que contemplem o potencial destas novas tecnologias, dentro desta nova lógica/razão dinâmica do mundo contemporâneo.

É imprescindível, também, a percepção de que esse projeto pedagógico deve movimentar-se de forma hipertextual, ultrapassando a ênfase meramente instrumental, para cumprir a tarefa de formação humana (Mais do que máquinas, homens é que sois! dizia Chaplin), de produção e socialização do conhecimento. Conhecimentos que sejam úteis ao homem, educando-o para a cidadania. Servir-se dessa técnica para uma produção cole- 
tiva que demande o exercício pleno da cidadania. Este é o caminho para que tenhamos a tecnologia a serviço da produção de conhecimento e assim construirmos a escola de que nos fala Rubem Alves: "um espaço onde se servem às nossas crianças os aperitivos do futuro em direção ao qual os nossos corpos se inclinam e os nossos sonhos voam"17.
Resumo: $\mathrm{O}$ artigo discute as mudanças geradas pelo avanço das tecnologias da informação e da comunicação na sociedade contemporânea e a conseqüente alteração de conceitos educacionais. Faz uma reflexão sobre a construção de uma outra forma de perceber a realidade, principalmente a partir das tecnologias denominadas inteligentes. Destaca a necessidade de a escola considerar estas tecnologias enquanto produtoras de conhecimento. Discute, por outro lado, fatores como a centralização dos meios de informação e comunicação, além da exclusão e do desemprego gerados pelas formas de apropriação centralizadas da tecnologia. A autora, diante deste quadro, apresenta o desafio da construção de um currículo numa lógica hipertextual, através do qual o educador crie possibilidades para troca de idéias, de informações, de saberes múltiplos, diferentes e, por isso mesmo, ricos. Os conteúdos trabalhados no interior deste currículo deixam de ser aqueles direcionados por um poder hegemônico centralizado, para ser um conteúdo que responda inicialmente às exigências dos diferentes grupos sociais e, em seguida, possibilite a inserção dos membros destes grupos no mundo globalizado de forma crítica.

Palavras-chave: tecnologias, professor, exclusão, curriculo, cidadania, hipertexto
Abstract: The article discusses the changes brought on by information and communication technology advances on contemporaneous society and the consequent change in educational concepts. It reflects on the construction of a different manner to perceive reality, especially based on the so-called intelligent technologies. The article stresses the need for the school to consider these technologies as knowledge producers. On the other hand, it also discusses factors such as means of information and communication centralization, over and beyond exclusion and unemployment generated by the centralized appropriation of technology. The author, considering this picture, presents the challenge of building a curriculum using a hypertextual logic through which the educator creates possibilities to exchange multiple and different ideas and information, in other words, rich knowledge. The content worked on within this curriculum is no longer the one directed by a hegemonic and centralized power, but, rather, one in which content responds initially to the demands of the different social groups and, then, allows for the insertion of the members of these groups in a globalized world in a critical manner.

Key words: technologies, teacher, exclusion, curriculum, citizenship, hypertext 